\title{
Gnidia glauca flower extract mediated synthesis of gold nanoparticles and evaluation of its chemocatalytic potential
}

\author{
Sougata Ghosh'1, Sumersing Patil ${ }^{1}$, Mehul Ahire ${ }^{1}$, Rohini Kitture ${ }^{2}$, Deepanjali D Gurav ${ }^{3}$, Amit M Jabgunde $^{3}$, \\ Sangeeta Kale ${ }^{4}$, Karishma Pardesi ${ }^{5}$, Vaishali Shinde ${ }^{3}$, Jayesh Bellare ${ }^{6}$, Dilip D Dhavale ${ }^{3}$ and Balu A Chopade ${ }^{1^{*}}$
}

\begin{abstract}
Background: Novel approaches for synthesis of gold nanoparticles (AuNPs) are of utmost importance owing to its immense applications in diverse fields including catalysis, optics, medical diagnostics and therapeutics. We report on synthesis of AuNPs using Gnidia glauca flower extract (GGFE), its detailed characterization and evaluation of its chemocatalytic potential.

Results: Synthesis of AuNPs using GGFE was monitored by UV-Vis spectroscopy and was found to be rapid that completed within 20 min. The concentration of chloroauric acid and temperature was optimized to be $0.7 \mathrm{mM}$ and $50^{\circ} \mathrm{C}$ respectively. Bioreduced nanoparticles varied in morphology from nanotriangles to nanohexagons majority being spherical. AuNPs were characterized employing transmission electron microscopy, high resolution transmission electron microscopy. Confirmation of elemental gold was carried out by elemental mapping in scanning transmission electron microscopic mode, energy dispersive spectroscopy and X-ray diffraction studies. Spherical particles of size $\sim 10 \mathrm{~nm}$ were found in majority. However, particles of larger dimensions were in range between 50-150 nm. The bioreduced AuNPs exhibited remarkable catalytic properties in a reduction reaction of 4-nitrophenol to 4-aminophenol by $\mathrm{NaBH}_{4}$ in aqueous phase.
\end{abstract}

Conclusion: The elaborate experimental evidences support that GGFE can provide an environmentally benign rapid route for synthesis of AuNPs that can be applied for various purposes. Biogenic AuNPs synthesized using GGFE exhibited excellent chemocatalytic potential.

Keywords: Gnidia glauca, Gold nanoparticles, UV-Visible spectroscopy, Transmission electron microscopy, High resolution transmission electron microscopy, Elemental mapping, Energy dispersive spectroscopy, Dynamic light scattering, $\mathrm{X}$-ray diffraction, Chemocatalysis

\section{Background}

Nanomaterials of various shapes and sizes have been the subject of utmost interest due to their potential applications in industries, biomedical diagnostics and electronics, over the past decade [1-10]. Most of the available chemical processes for synthesis of gold nanoparticles (AuNPs) involve toxic chemicals that get adsorbed on the surface, leading to adverse effects in medical applications. Presently there is a growing need to develop environmentally benign process for rapid synthesis of nanoparticles [11].

\footnotetext{
* Correspondence: directoribb@unipune.ac.in

1 Institute of Bioinformatics and Biotechnology, University of Pune,

Pune 411007, India

Full list of author information is available at the end of the article
}

At present, biological methods have an increasing interest because of the necessity to develop new clean, cost-effective and efficient synthesis techniques. Lately, many biological systems such as bacteria, yeast, fungi and several plant extracts have been investigated due to their ability to reduce metal ions and form nanoparticles [12-22]. Synthesis of nanoparticles employing plants can potentially render more biocompatibility to the nanoparticles [23-25].

Plant mediated synthesis of metal nanoparticles is gaining more importance owing to its simplicity, rapid rate of synthesis of nanoparticles of attractive and diverse morphologies and elimination of elaborate maintenance of cell cultures and eco-friendliness. It is reported that Achillea wilhemsii flowers can be used for synthesis of

\section{() Biomed Central}


highly stable AuNPs [26]. AuNPs has drawn special attention owing to its immense importance in biomedical and chemical applications [27,28]. Among the array of applications, the reduction of 4-nitrophenol (4-NP) to 4aminophenol (4-AP) using noble metal nanoparticles as catalysts has become one of the significant model reactions (Figure 1). AuNPs can effectively catalyze the reduction of nitro compounds by the electron transfer from donor $\mathrm{BH}_{4}^{-}$to acceptor nitro groups. The reduction process is monitored through measuring the change of absorbance at $400 \mathrm{~nm}$ as a function of time.

In this work, we have investigated the biosynthesis of AuNPs using Gnidia glauca flower extract (GGFE) as a clean technology. G. glauca is an endemic flora of Western Ghats of India. It has an array of medicinal applications in sore throat, abdominal pain, wounds, burns, and snake bites, contusions, swellings, back ache, and joint ache $[29,30]$. Recently, we have reported its antidiabetic property [31]. However, there are no reports till date that documents its potential in nanobiotechnology to synthesize nanoparticles and thereby evaluating its chemocatalytic applications.

Herein, we report the biogenic synthesis of AuNPs using aqueous extract of G. glauca flower for reduction of $\mathrm{Au}^{3+}$ ions. We also investigated the effects of reaction conditions such as time course, reaction temperature and concentration of chloroauric acid on the rate of synthesis of the AuNPs. Further, we demonstrated its chemocatalytic potential in reduction of 4-nitrophenol (4-NP) to 4-aminophenol (4-AP).

\section{Results and discussion}

\section{Biosynthesis of AuNPs by GGFE}

Reduction of $\mathrm{Au}^{3+}$ to AuNPs by GGFE could be followed by color change from yellow to ruby red (Figure 2) and further by UV-vis spectroscopy. The peak observed at $540 \mathrm{~nm}$ confirmed the synthesis of AuNPs as it is in agreement with the previous reports [11]. Though initially there was no significant peak at $2 \mathrm{~min}$ but at $4 \mathrm{~min}$ the building of peak at $540 \mathrm{~nm}$ marked the initiation of synthesis of AuNPs. Subsequent rise in peak with a maximum

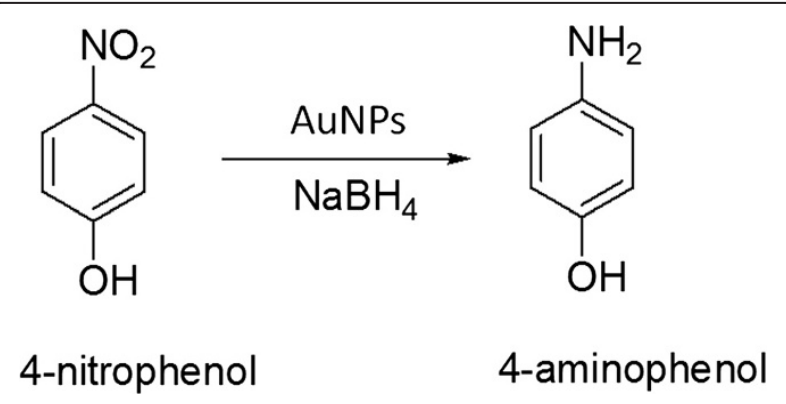

Figure 1 Scheme for chemical catalysis from 4-nitrophenol to 4-aminophenol. at 20 min supported that the reported route of AuNPs synthesis is novel as well as rapid as compared to Mirabilis jalapa flower wherein the synthesis was reported to be completed in $2 \mathrm{~h}$ [32]. Similarly, it was found to be faster even as compared to black tea extract [33]. Optimization studies showed that $0.7 \mathrm{mM}$ of chloroauric acid facilitated maximum synthesis of AuNPs as compared to other concentrations (Figure 3). The effect of concentration of chloroauric acid on the kinetics of the synthesis of AuNPs was found to be prominent as although the rate of synthesis increased with concentration till $1 \mathrm{mM}$, at higher concentration there was no synthesis. Temperature optimization revealed a direct effect on the reaction kinetics (Figure 4). Synthesis failed to be initiated at lower temperatures like 4 and $20^{\circ} \mathrm{C}$ while a moderate rate of reaction was observed at 30 and $40^{\circ} \mathrm{C}$. The rate of reaction was found to be maximum at $50^{\circ} \mathrm{C}$ which supported the fact that higher temperature plays a key role in enhancing the reaction rate which is in well agreement with synthesis of AuNPs mediated by Nyctanthes arbortristis flower extract [34].

\section{TEM, HRTEM and DLS}

The size and shape of the bioreduced AuNPs were elucidated with the help of TEM. TEM images in (Figure 5) confirm the formation of AuNPs. The figure nicely illustrates that most of the particles were spherical in a range of 5 to $20 \mathrm{~nm}$ as was reported in case of other plant extracts as well $[35,36]$. Pronounced anisotropy among the bioreduced nanoparticles was evident from the nanotriangles and nanoprisms (Figure 5a) which is similar to Rosa hybrida petal extract which is reported to synthesize polydispersed AuNPs [37]. Shape evolution, particularly triangles are attributed owing to the chloride ions contributed by the chloroauric acid [11]. In some cases nanoparticles were found in small aggregates adsorbed onto the surface of the particles with larger dimensions between 50 to $150 \mathrm{~nm}$ (Figure 5d). Similarly, HRTEM images provided valuable information about the architecture of the biogenic AuNPs. Figure 6a shows the anisotropy among the bioreduced nanoparticles and their positioning by attachment on the surface of each other. Very small nanospheres could be spotted in Figure 6b. Spherical nanoparticles are reported to be formed at low extract concentration when the extract has excellent capping and stabilizing property [36]. Figure $6 \mathrm{c}$ and $\mathrm{d}$ show the fine nanostructure of the hexagons and triangles with equilateral edges. Elemental mapping on scanning transmission electron microscopic mode confirmed the bioreduced nanoparticles employing GGFE was elemental gold (Figure 6f).

In the analysis of synthesized particles by energy dispersive spectroscopy (EDS), the presence of elemental gold signal was confirmed (Figure 7). Particle size distribution of the AuNPs determined by dynamic light scattering is 


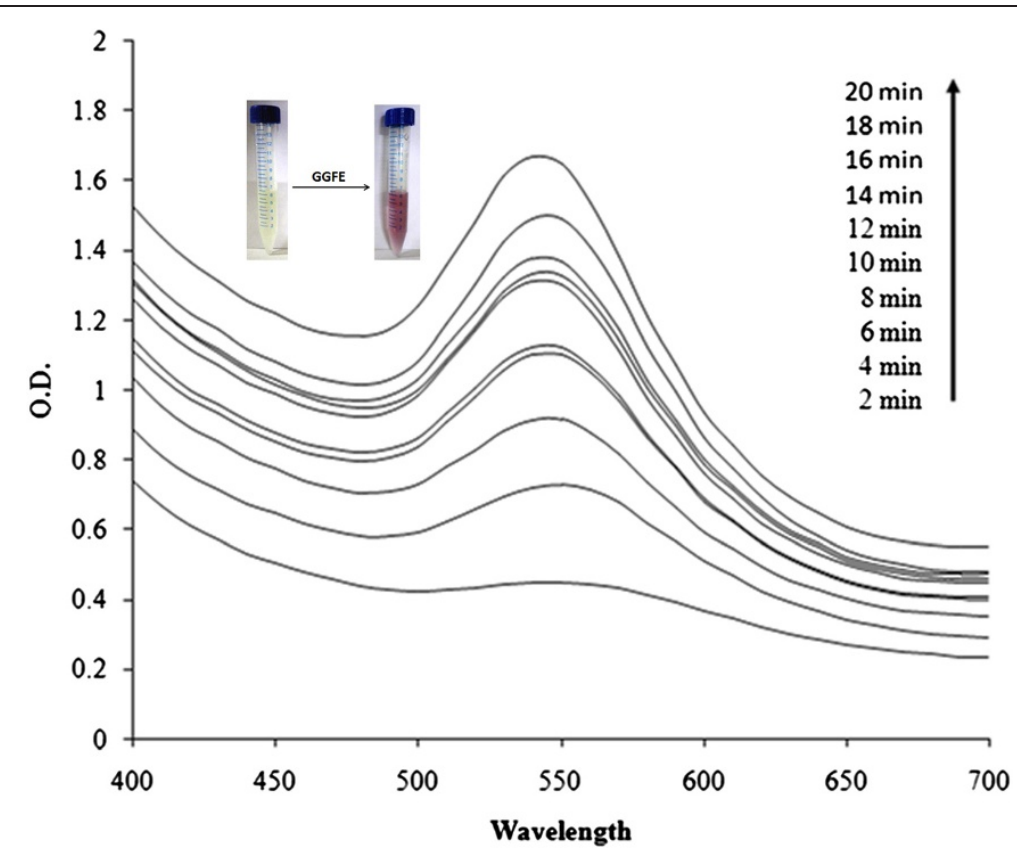

Figure 2 UV-vis spectra recorded as a function of reaction time of $1 \mathrm{mM}$ chloroauric acid solution with GGFE at $40^{\circ} \mathrm{C}$.

shown in Figure 8 which was found well in agreement with TEM and HRTEM analysis.

\section{XRD analysis}

The phase formation of the synthesized AuNPs was analysed employing X-ray diffraction which confirmed that the bioreduced metal nanoparticles are of elemental gold (Figure 9). Existance of peaks (111), (200), (220) and (311) matched with the standard Joint Committee for Powder
Diffraction Set (JCPDS) data- 04784. This confirmed face centered cubic structured AuNPs formation. Peak broadening indicated restricted particle size. Enlarged pattern of (111) peak is shown in the inset of XRD plot. The crystallite size was calculated using Scherrer's formula

$$
d=\frac{0.9 \lambda}{\beta \cos \theta}
$$

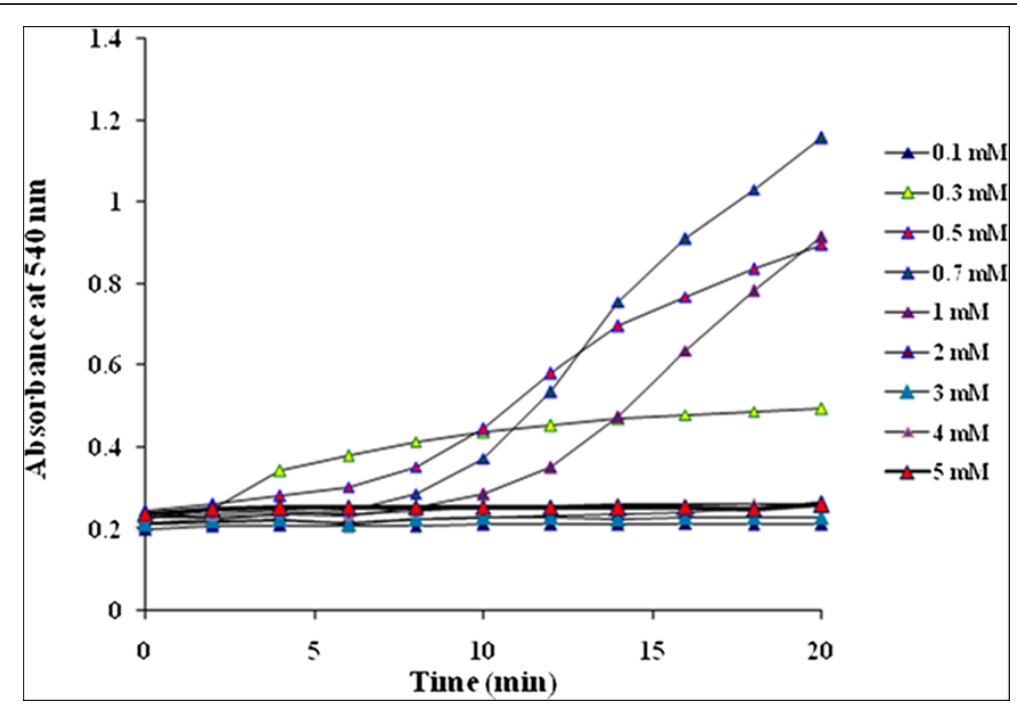

Figure 3 Time course of AuNPs formation obtained with different concentrations of chloroauric acid using GGFE at $40^{\circ} \mathrm{C}$. 


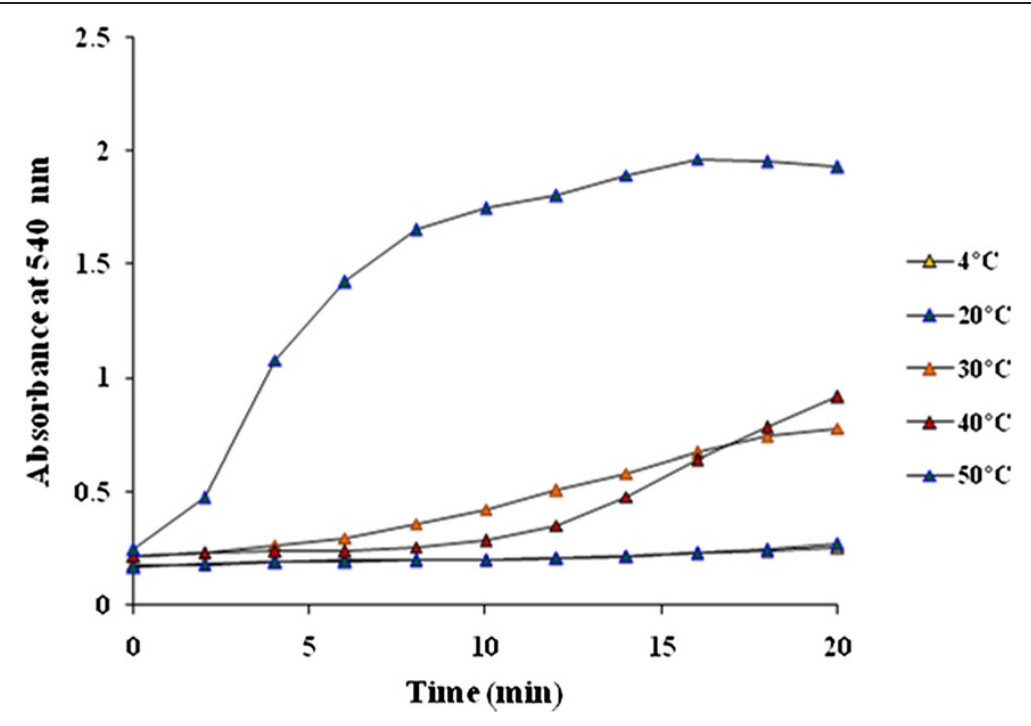

Figure 4 Time course of AuNPs formation obtained with $1 \mathrm{mM}$ chloroauric acid using GGFE at different reaction temperature.

Here 0.9 is the shape factor, generally taken for a cubic system, $\lambda$ is the $\mathrm{x}$-ray wavelength, typically $1.54 \AA$, $\beta$ is the full width at half the maximum intensity (FWHM) in radians, and $\theta$ is the Bragg angle. Using the above formula the crystallite size calculated is $\sim 10 \mathrm{~nm}$.

\section{Fourier Transform Infrared Spectroscopy (FTIR) analysis} FTIR absorption spectra GGFE before and after reduction of $\mathrm{Au}^{3+}$ are shown in Figure 10. GGFE before bioreduction
(Figure 10a) shows strong peak at $\sim 3300 \mathrm{~cm}^{-1}$ which is a characteristic of hydroxyl group in alcoholic and phenolic compounds. Free water soluble flavonoids are reported to play a major role in the biogenic synthesis and stabilization of AuNPs employing Syzygium aromaticum flower [38,39]. The sharp peak at $1607 \mathrm{~cm}^{-1}$ along with other at $\sim 1450 \mathrm{~cm}^{-1}$ represents $\mathrm{C}=\mathrm{C}$ characteristic group of phenols [40]. Bonds in the range $1220-1240 \mathrm{~cm}^{-1}$ represent aliphatic amines. This gives evidence of existence of amine group in
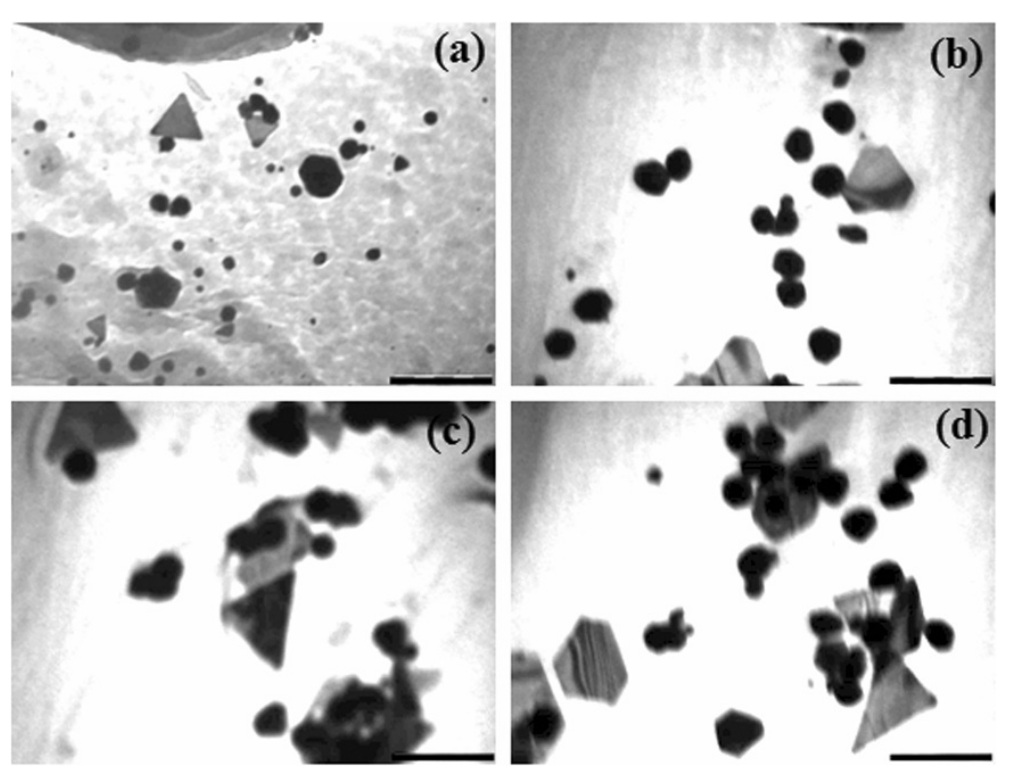

Figure 5 Characterization of AuNPs formed with $1 \mathrm{mM}$ chloroauric acid and $5 \%$ GGFE at $40^{\circ} \mathrm{C}$ by transmission electron microscopy (TEM). (a) Anisotropic gold nanotriangles; (b) Gold nanotrapezoids; (c) Gold nanospheres and triangles with equilateral edges ; (d) Gold nanotrapezoids and spherical nanoparticles adsorbed on surface of triangles. The inset bars represent $200 \mathrm{~nm}$. 


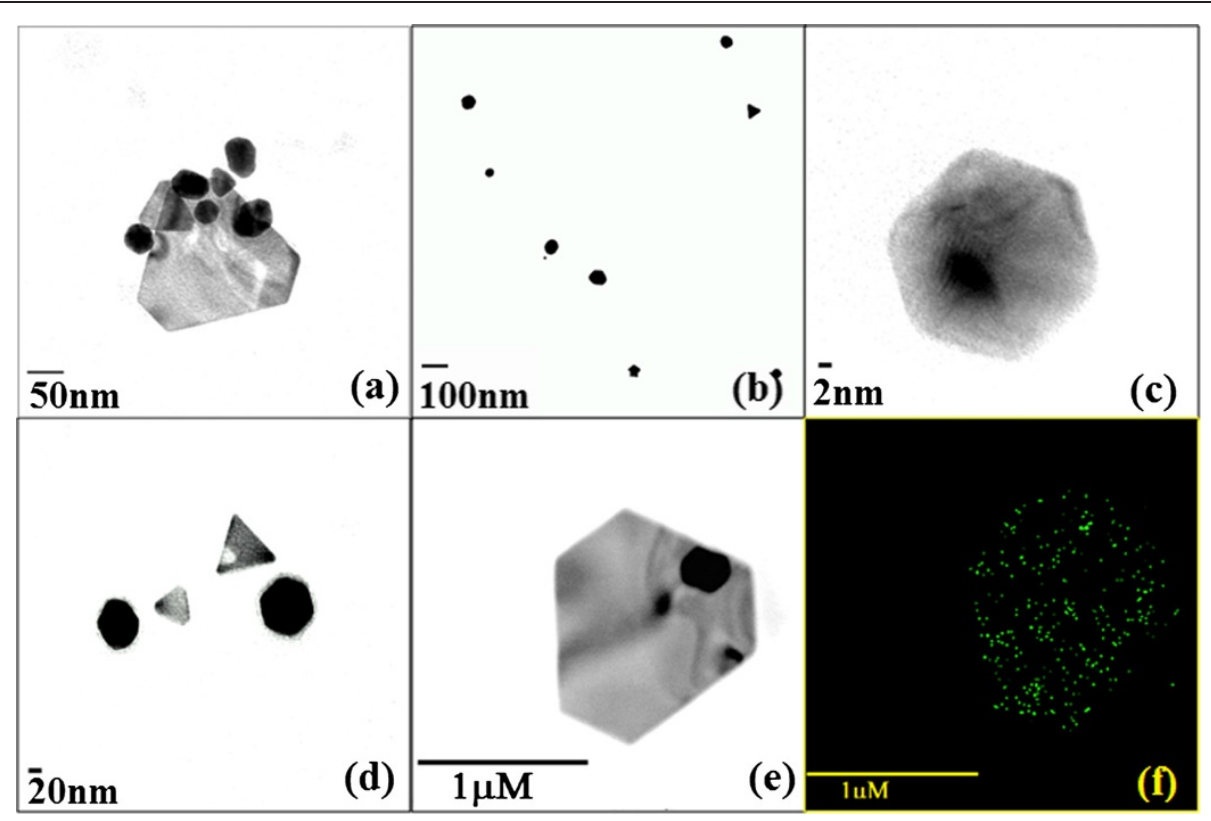

Figure 6 Characterization of AuNPs formed with $1 \mathrm{mM}$ chloroauric acid and $5 \%$ GGFE at $40^{\circ} \mathrm{C}$ by high resolution transmission electron microscopy (HRTEM). (a) Anisotropic AuNPs adsorbed on surface of each other; (b) Spherical nanoparticles in a range of $10 \mathrm{~nm}$.; (c) Gold nanohexagon with equilateral edges; (d) Gold nanotriangles and hexagons; (e) Scanning transmission mode micrographs for gold nanotrapezoid.; (f) Elemental mapping of gold nanotrapezoid.

GGFE. Existence of alcohol group was supported by the peak at $\sim 1100 \mathrm{~cm}^{-1}$. These four peaks present before and after synthesis of nanoparticle may also indicate that GGFE may play a role in stabilizing AuNPs by adsorbing on the surface of bioreduced AuNPs. A small peak shift at $\sim 2930 \mathrm{~cm}^{-1}$ may indicate bonding of extract to the AuNPs. $\mathrm{C}-\mathrm{H}$ stretches of alkanes appear from $3000-2850 \mathrm{~cm}^{-1}$ may be due to bonding of alkanes present in GGFE to AuNPs.

\section{Chemoctalytic property of AuNPs}

In alkaline $\mathrm{NaBH}_{4}$ medium, the absorption peak at $317 \mathrm{~nm}$ for 4-NP showed bathochromic shift at $400 \mathrm{~nm}$ due to formation of 4-nitrophenolate ion. As the reduction reaction does not proceed without catalyst, the peak (400 $\mathrm{nm})$ due to 4- nitrophenolate remained unaltered. After addition of catalytic amount of AuNPs, the peak at $400 \mathrm{~nm}$ due to 4-NP decreased in intensity while a new peak at $300 \mathrm{~nm}$ appeared due to formation of 4-AP. This

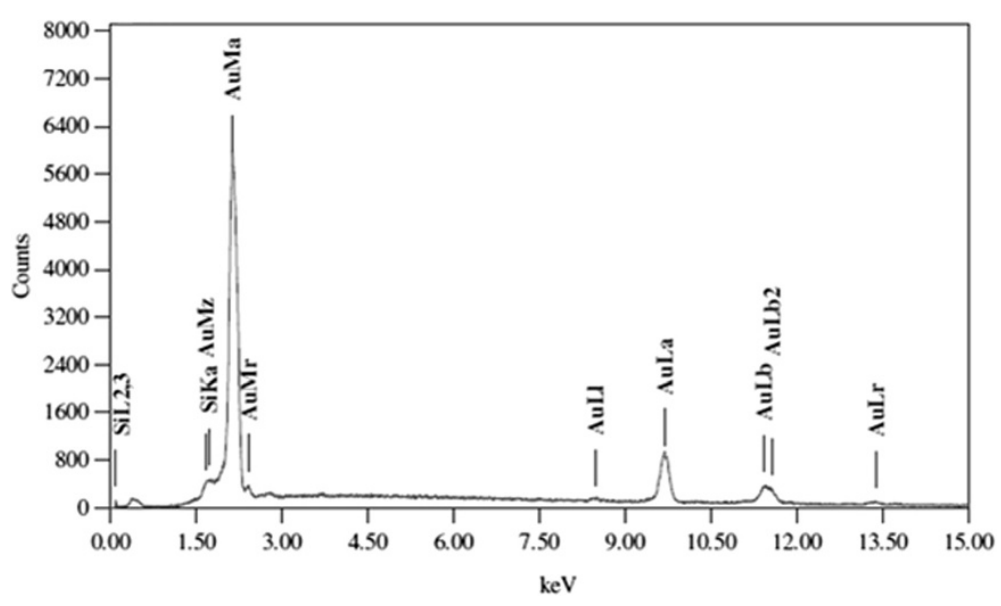

Figure 7 Representative spot EDS profile confirming the presence of AuNPs. 


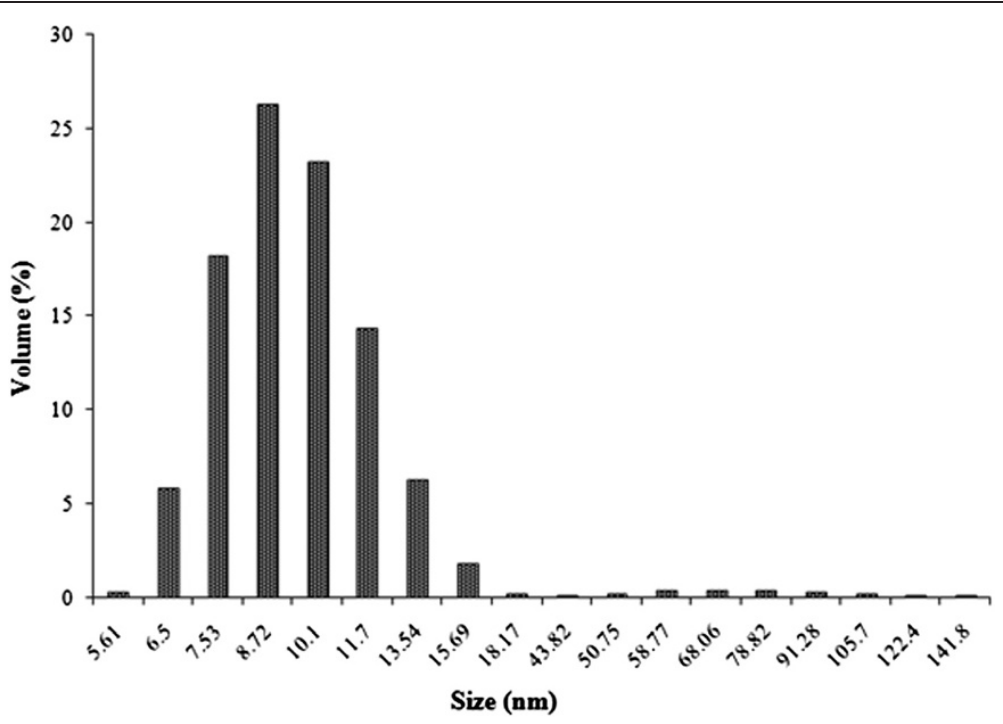

Figure 8 A histogram of size distribution of AuNPs synthesized by GGFE.

observation showed that the AuNPs catalyzed the reduction reaction which is primarily a size and shape dependent phenomena [41-43]. As the concentration of $\mathrm{NaBH}_{4}$ used was much higher than that of 4-NP, the order of the reaction was considered to be pseudo-first order reaction which is in agreement with Gangula et al [44]. Inset of Figure 11 shows a good linear correlation of $\ln \left(A_{t} / A_{O}\right)$ versus time and the kinetic rate reaction constant was estimated to be $1.78 \times 10^{-2} \mathrm{~min}^{-1}$. $\left(A_{t}\right.$ : absorbance at $400 \mathrm{~nm}$ at time $t, A_{0}$ : absorbance at $400 \mathrm{~nm}$ at $\left.t=0\right)$.

\section{Conclusion}

In conclusion GGFE mediated synthesis of AuNPs has been demonstrated to be a rapid and environmentally

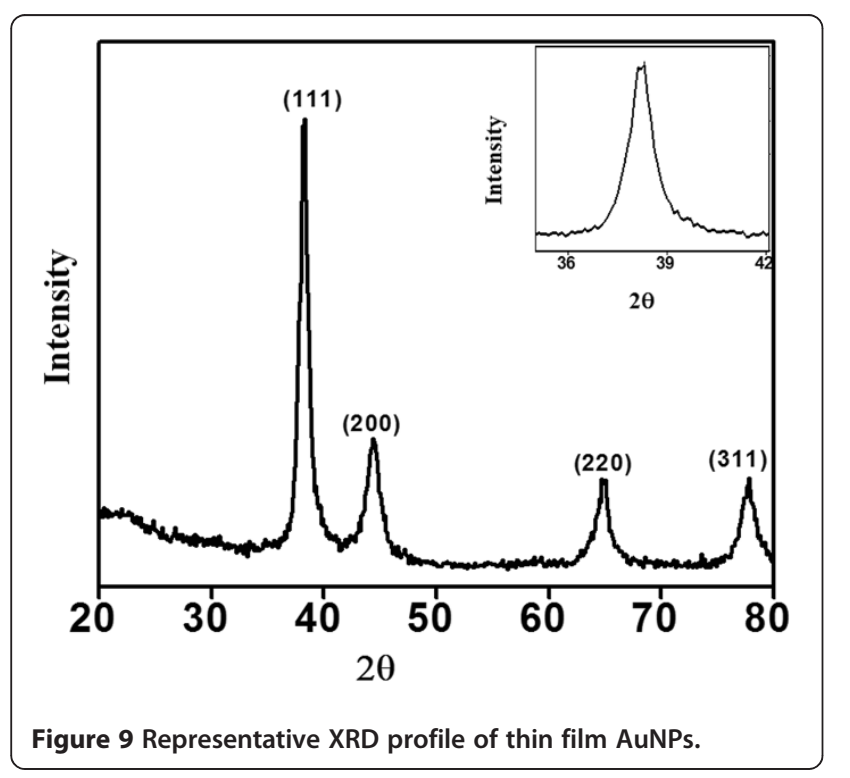

benign route. Variation of reaction conditions had pronounced effect on the reaction kinetics. Optimum conditions for maximum synthesis were found to be $0.7 \mathrm{mM}$ of chloroauric acid at $50^{\circ} \mathrm{C}$. AuNPs with exotic shapes like nanoprisms, nanotriangles, hexagons trapezoids were synthesized. Spherical nanoparticles were in abundance which were found to be face centered cubic (FCC) structured gold (111). Bioreduced AuNPs showed excellent catalytic properties in a reduction reaction of 4-nitrophenol to 4-aminophenol by $\mathrm{NaBH}_{4}$ in aqueous phase. Thus this rapid, eco-friendly and economical route can be used to

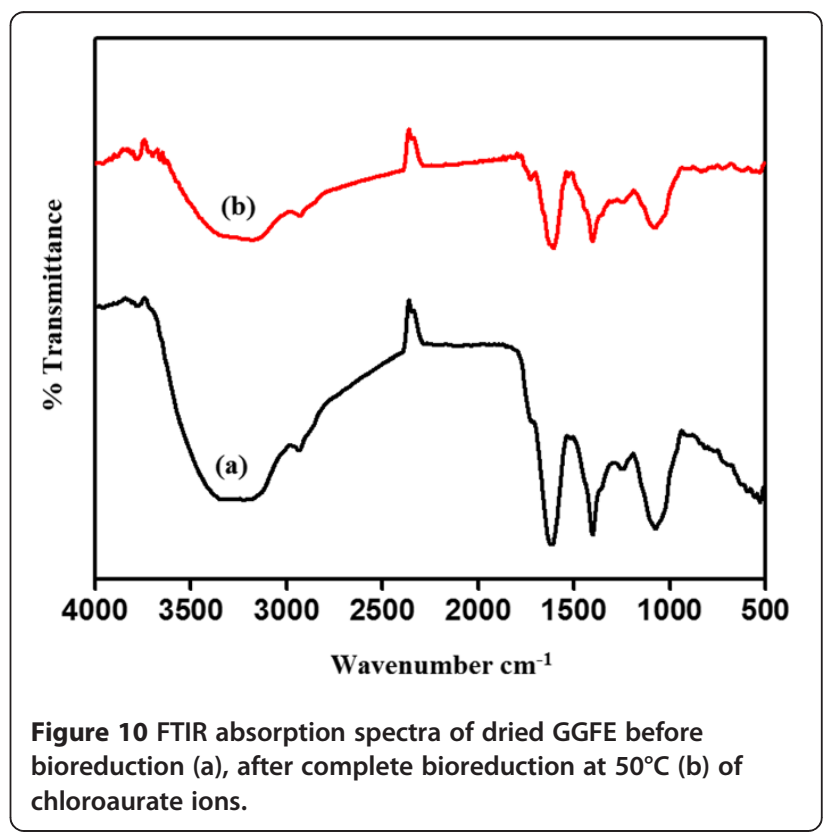




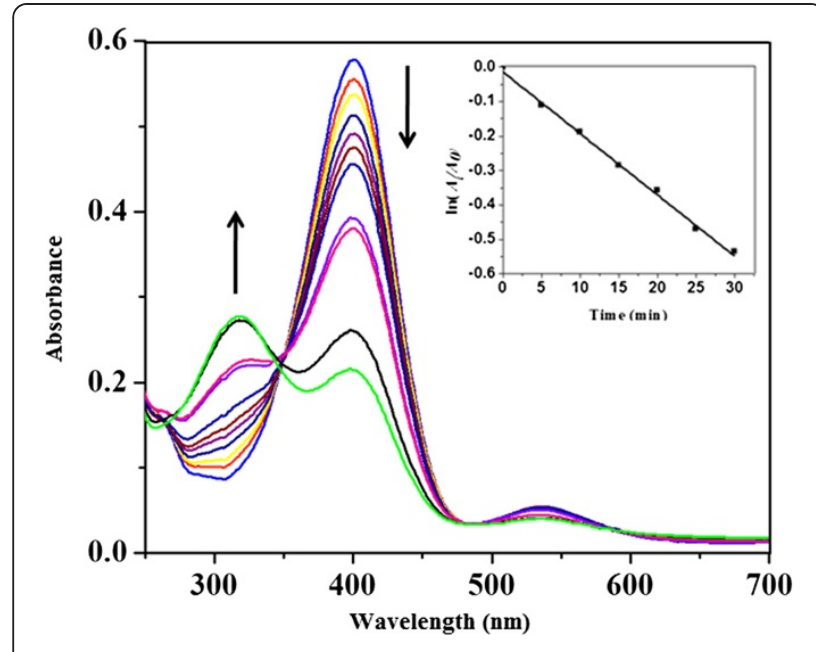

Figure 11 Time dependent UV-vis spectra for monitoring 4-nitrophenol reduction by $\mathrm{NaBH}_{4}$ catalyzed by AuNPs. The inset shows the plot indicating the variation of $\ln \left(A_{t} / A_{0}\right)$ vs time.

synthesize AuNPs with wide biotechnological and chemical applications.

\section{Materials and methods}

Plant material and preparation of extract

G. glauca flowers were collected from Western Ghats of Maharashtra, India. The flowers were thoroughly washed in running tap water for $15 \mathrm{~min}$ and then shade dried for 2 days at room temperature. Dry flowers were ground into fine powder in an electric blender. $5 \mathrm{~g}$ of this powder was suspended in $100 \mathrm{~mL}$ of distilled water in a $300 \mathrm{~mL}$ Erlenmeyer flask followed by boiling for $5 \mathrm{~min}$ before finally decanting it. The extract obtained was filtered through Whatman filter paper No.1. The filtrate was collected and stored at $4^{\circ} \mathrm{C}$ which was used throughout all the experiments.

\section{Synthesis of gold nanoparticles}

Reduction of $\mathrm{Au}^{3+}$ ions was initiated by addition of $5 \mathrm{~mL}$ of GGFE to $95 \mathrm{~mL}$ of $10^{-3} \mathrm{M}$ aqueous chloroauric acid solution in a $500 \mathrm{~mL}$ Erlenmeyer flask. The $\mathrm{pH}$ of the extract was found to be neutral. Thereafter, the flasks were shaken at a rotation rate of $150 \mathrm{rpm}$ in the dark at $40^{\circ} \mathrm{C}$. Reduction of the $\mathrm{Au}^{3+}$ ions was monitored by measuring the UV-vis spectra of the solution at regular intervals on a UV-1650CP Schimadzu spectrophotometer operated at resolution of $1 \mathrm{~nm}$. Effects of temperature and concentration of chloroauric acid on the rate of AuNPs were studied by carrying out the reaction in water bath at 4$50^{\circ} \mathrm{C}$ with reflux and by varying the concentration of chloroauric acid from 0.1-5 $\mathrm{mM}$.
Transmission Electron Microscopy (TEM), High Resolution Transmission Electron Microscopy (HRTEM) and Dynamic Light Scattering (DLS) measurements

Morphology of the bioreduced AuNPs was studied by transmission electron microscopy (Tecnai 12 cryo TEM, FEI, Netherland). Further the size and shape of the AuNPs were characterized by JEOL-JEM-2100 higher resolution transmission electron microscope (HRTEM) coupled with elemental composition mapping under scanning transmission electron microscopic mode (STEM). Energy dispersive spectra of AuNPs was taken in the energy dispersive spectrometer (EDS) equipped in JEOL JSM 6360A analytical scanning electron microscope at an energy range $0-20 \mathrm{keV}$ confirmed the synthesis of AuNPs using GGFE. The size of particles was analyzed by using the dynamic light scattering equipment (Zetasizer Nano2590, Malvern Instruments Ltd, Worcestershire, UK) in $3 \mathrm{~mL}$ of reaction mixture in a polysterene cuvette.

\section{$\mathrm{X}$ ray diffraction $(\mathrm{XRD})$ measurements}

The phase formation of bio-reduced AuNPs was studied with the help of XRD. The diffraction data of thoroughly dried thin films of nanoparticles on glass slides was recorded on D 8 Advanced Brucker $\mathrm{X}$ ray diffractometer with $\mathrm{Cu} \mathrm{K \alpha}(1.54 \AA)$ source.

\section{Fourier Transform Infrared (FTIR) spectroscopy}

AuNPs synthesized after 20 min of reaction between $1 \mathrm{mM}$ chloroauric acid solution and GGFE were centrifuged at 10,000 rpm for $15 \mathrm{~min}$ at room temperature, following which the pellet was redispersed in sterile distilled water to remove any uncoordinated biological molecules. In order to ensure better separation of free entities from the nanoparticles, the process of centrifugation and redispersion in sterile distilled water was repeated thrice. The purified pellet was then dried and subjected to FTIR (Shimadzu IR Affinity) spectroscopy measurement using the potassium bromide $(\mathrm{KBr})$ pellet technique in the diffused reflection mode at a resolution of $4 \mathrm{~cm}^{-1}$. Au nanoparticle powder was mixed with $\mathrm{KBr}$ and subjected to IR source $500-4000 \mathrm{~cm}^{-1}$. Similar process was used for the FTIR study of GGFE before and after bioreduction.

\section{Catalytic reduction of 4-nitrophenol}

The catalytic reduction of 4-NP was studied in a standard quartz cuvette by adding $0.8 \mathrm{~mL}$ of aqueous $\mathrm{NaBH}_{4}$ solution $(1.0 \mathrm{mM})$ to $1.0 \mathrm{~mL}$ of $4-\mathrm{NP}$ aqueous solution $(0.1 \mathrm{mM})$. Then $200 \mu \mathrm{L}$ of aqueous suspension of AuNPs (0.1 $\mathrm{mM})$ was introduced into the solution and time dependent absorption spectra were recorded after every $5 \mathrm{~min}$ in the range of $200-800 \mathrm{~nm}$ at $25^{\circ} \mathrm{C}$. The progress of reaction was monitored by UV- visible spectrophotometer as both the starting material, 4-NP and the 
product 4-AP shows a different absorption in the UVvisible region.

\section{Competing interests}

The authors declare that they have no competing interests.

\section{Acknowledgements}

S. Ghosh thanks Council of Scientific and Industrial Research (CSIR, Government of India) for Senior Research Fellowship (09/137(0516)/2012EMR-I). Authors acknowledge Institute of Bioinformatics and Biotechnology, University of Pune, Pune-411007, India for financial support for the work. The authors acknowledge use of TEM facilities in Chemical Engineering and CRNTS funded by the DST through Nanomission and IRPHA schemes. The authors thank Dr. M. Jayakannan, Indian Institute of Science Education and Research (IISER), Pune for DLS facility.

\section{Author details}

'Institute of Bioinformatics and Biotechnology, University of Pune, Pune 411007, India. ${ }^{2}$ Department of Electronic Science, Fergusson College, Pune 411004, India. ${ }^{3}$ Department of Chemistry, Garware Research Centre, University of Pune, Pune 411007, India. ${ }^{4}$ Department of Applied Physics, Defense Institute of Advanced Technology, Girinagar, Pune 411025, India. ${ }^{5}$ Department of Microbiology, University of Pune, Pune 411007, India. ${ }^{6}$ Department of Chemical Engineering, Indian Institute of Technology, Bombay, Powai, Mumbai 400076, India.

\section{Authors' contributions}

SG carried out the synthesis UV-Vis spectroscopic experimentation, optimization of temperature and concentration and data interpretation. SP designed the experimentation and data interpretation and manuscript writing of HRTEM and elemental map analysis. MA carried out the plant selection, processing, extract preparation and determination of size by DLS and data interpretation. RK and SK carried on the FTIR and XRD analysis, interpretation and manuscript writing. VSS and DDG conceived the idea and designed the study for the chemical catalysis and its detailed data interpretation. DDD, JAM, BAC and KP concieved the study, participated in its design, coordination, scientific drafting, editing and correcting the manuscript. All authors read and approved the final manuscript.

Received: 2 January 2012 Accepted: 1 May 2012

Published: 1 May 2012

\section{References}

1. Chatterjee S, Bandyopadhyay A, Sarkar K: Effect of iron oxide and gold nanoparticles on bacterial growth leading towards biological application. J Nanobiotechnology 2011, 9:34.

2. Soloviev M: Nanobiotechnology today: focus on nanoparticles. J Nanobiotechnology 2007, 5:11.

3. Wang J: Nanomaterial-based electrochemical biosensors. Analyst 2005, 130:421-426.

4. Pumera M, Sánchez S, Ichinose I, Tang J: Electrochemical nanobiosensors. Sens Actuators B Chem 2007, 123:1195-1205.

5. Castañeda MT, Alegret S, Merkoçi A: Electrochemical sensing of DNA using gold nanoparticles. Electroanalysis 2007, 19:743-753.

6. Wang J: Nanoparticle-based electrochemical DNA detection. Anal Chim Acta 2003, 500:247-257.

7. Farrell D, Alper J, Ptak K, Panaro NJ, Grodzinski P, Barker AD: Recent advances from the national cancer institute alliance for nanotechnology in cancer. ACS Nano 2010, 4:589-594.

8. Ferrari M: Cancer nanotechnology: opportunities and challenges. Nat Rev Cancer 2005, 5:161-171.

9. Rosi NL, Mirkin CA: Nanostructures in biodiagnostics. Chem Rev 2005, 105:1547-1562.

10. Gunasekera UA, Pankhurst QA, Douek M: Imaging applications of nanotechnology in cancer. Target Oncol 2009, 4:169-181.

11. Ghosh S, Patil S, Ahire M, Kitture R, Jabgunde A, Kale S, Pardesi K, Bellare JR, Dhavale DD, Chopade BA: Synthesis of gold nano-anisotrops using Dioscorea bulbifera tuber extract. J Nanomater 2011. doi:10.1155/2011/354793.

12. Liangwei D, Hong J, Xiaohua L, Erkang W: Biosynthesis of gold nanoparticles assisted by Escherichia coli DH5a and its application on direct electrochemistry of hemoglobin. Electrochem Commun 2007, 9:1165-1170.

13. Ahmad A, Senapati S, Khan Ml, Kumar R, Sastry M: Extracellular biosynthesis of monodisperse gold nanoparticles by a novel extremophilic actinomycete, Thermomonospora sp. Langmuir 2003, 19:3550-3553.

14. Ahmad A, Mukherjee P, Senapati S, Mandal D, Khan MI, Kumar R, Sastry M: Extracellular biosynthesis of silver nanoparticles using the fungus Fusarium oxysporum. Colloids Surf B Biointerfaces 2003, 28:313-318.

15. Ahmad A, Senapati S, Khan MI, Ramani R, Srinivas V, Sastry M: Intracellular synthesis of gold nanoparticles by a novel alkalotolerant actinomycete, Rhodococcus species. Nanotechnology 2003, 14:824-828.

16. Kowshik M, Ashtaputre S, Kharrazi S, Vogel W, Urban J, Kulkarni S, Paknikar K: Extracellular synthesis of silver nanoparticles by a silver tolerant yeast strain MKY3. Nanotechnology 2003, 14:95-100.

17. Sastry M, Ahmad A, Khan I, Kumar R: Biosynthesis of metal nanoparticles using fungi and actinomycete. Curr Sci 2003, 85:162-170.

18. Mukherjee P, Ahmad A, Mandal D, Senapati S, Sainkar SR, Khan MI, Parischa R, Ajaykumar PV, Alam M, Kumar R, Sastry M: Fungus mediated synthesis of silver nanoparticles and their immobilization in the mycelial matrix: a novel biological approach to nanoparticle synthesis. Nano Lett 2001, 1:515-519.

19. Iravani S: Green synthesis of metal nanoparticles using plants. Green Chem 2011, 13:2638-2650.

20. Ghosh S, Patil S, Ahire M, Kitture R, Jabgunde A, Kale S, Pardesi K, Cameotra SS, Bellare J, Dhavale DD, Chopade BA: Synthesis of silver nanoparticles using Dioscorea bulbifera tuber extract and evaluation of its synergistic potential in combination with antimicrobial agents. Int I Nanomedicine 2011, 7:483-496

21. Philip D: Green synthesis of gold and silver nanoparticles using Hibiscus rosa sinensis. Physica E Low Dimens Sys Nanostruct 2010, 42:1417-1424.

22. Satyavani K, Gurudeeban S, Ramanathan T, Balasubramanian T: Biomedical potential of silver nanoparticles synthesized from calli cells of Citrullus colocynthis (L.) Schrad. J Nanobiotechnology 2011, 9:43.

23. Vilchis-Nestor AR, Sánchez-Mendieta V, Camacho-López MA, GómezEspinosa RM, Camacho-López MA, Arenas-Alatorre JA: Solvent less synthesis and optical properties of $\mathrm{Au}$ and $\mathrm{Ag}$ nanoparticles using Camelia sinensis extract. Mater Lett 2008, 62:3103-3105.

24. Nune SK, Chanda N, Shukla R, Katti K, Kulkarni RR, Thilakavathy S, Mekapothula S, Kannan R, Katti KV: Green nanotechnology from tea: phytochemicals in tea as building blocks for production of biocompatible gold nanoparticles. J Mater Chem 2009, 19:2912-2920

25. Sinha S, Pan I, Chanda P, Sen SK: Nanoparticles fabrication using ambient biological resources. J Appl Biosci 2009, 19:1113-1130.

26. Andeani JK, Kazemi H, Mohsenzadeh S, Safavi A: Biosynthesis of gold nanoparticles using dried flowers extract of Achillea wilhelmsii plant. Dig J Nanomater Bios 2011, 6:1011-1017.

27. BarathManiKanth S, Kalishwaralal K, Sriram M, Pandian SBRK, Youn H, Eom SH, Gurunathan S: Antioxidant effect of gold nanoparticles restrains hyperglycemic conditions in diabetic mice. J Nanobiotechnology 2010, 8:16.

28. Wu H, Huang X, Gao M, Liao X, Shi B: Polyphenol-grafted collagen fiber as reductant and stabilizer for one-step synthesis of size-controlled gold nanoparticles and their catalytic application to 4-nitrophenol reduction. Green Chem 2011, 13:651-658.

29. Amarajeewa BWRC, Mudalige AP, Kumar V: Chemistry and mosquito larvicidal activity of G. glauca. In Proceedings of the Peradeniya University Research Sessions, SriLanka 2007, 12:101-102.

30. Kareru PG, Kenji GM, Gachanja AN, Keriko JM, Mungai G: Traditional medicines among the Embu and Mbeere peoples of Kenya. Afr J Tradit Complement Altern Med 2007, 4:75-86.

31. Ghosh S, Ahire M, Patil S, Jabgunde A, Bhat Dusane M, Joshi BN, Pardesi K Jachak S, Dhavale DD, Chopade BA: Antidiabetic activity of Gnidia glauca and Dioscorea bulbifera: Potent amylase and glucosidase inhibitors. Evid Based Complement Alternat Med 2011 2012. doi:10.1155/2012/929051.

32. Vankar PS, Bajpai D: Preparation of gold nanoparticles from Mirabilis jalapa flowers. Indian J Biochem Biophys 2010, 47:157-160.

33. Begum NA, Mondal S, Basu S, Laskar RA, Mandal D: Biogenic synthesis of $\mathrm{Au}$ and $\mathrm{Ag}$ nanoparticles using aqueous solutions of black tea leaf extracts. Colloids Surf B Biointerfaces 2009, 71:113-118.

34. Das RK, Gogoi N, Bora U: Green synthesis of gold nanoparticles using Nyctanthes arbortristis flower extract. Bioprocess Biosyst Eng 2011, 34:615-619.

35. Smitha SL, Philip D, Gopchandrana KG: Green synthesis of gold nanoparticles using Cinnamomum zeylanicum leaf broth. Spectrochim Acta A Mol Biomol Spectrosc 2009, 74:735-739. 
36. Philip D: Rapid green synthesis of spherical gold nanoparticles using Mangifera indica leaf. Spectrochim Acta A Mol Biomol Spectrosc 2010 77:807-810

37. Noruzi M, Zare D, Khoshnevisan K, Davoodi D: Rapid green synthesis of gold nanoparticles using Rosa hybrida petal extract at room temperature. Spectrochim Acta A Mol Biomol Spectrosc 2011, 79:1461-1465.

38. Deshpande R, Bedre MD, Basavaraja S, Sawle B, Manjunath SY, Venkataraman A: Rapid biosynthesis of irregular shaped gold nanoparticles from macerated aqueous extracellular dried clove buds (Syzygium aromaticum) solution. Colloids Surf B Biointerfaces 2010, 79:235-240.

39. Singh AK, Talat M, Singh DP, Srivastava ON: Biosynthesis of gold and silver nanoparticles by natural precursor clove and their functionalization with amine group. J Nanopart Res 2010, 12:1667-1675.

40. George Socrates: Infrared and Raman Characteristic group frequencies. Volume 99, 3rd edition. England: John Wiley \& sons Ltd; 2001:94-100.

41. Pradhan N, Pal A, Pal A: Silver nanoparticle catalyzed reduction of aromatic nitro compounds. Colloids Surf, A Physicochem Eng Asp 2002, 196:247-257.

42. Pfaff A, Shinde VS, Lu Y, Wittemann A, Ballauff M, Mueller AHE: Glycopolymer-grafted polystyrene nanospheres. Macromol Biosci 2011, 11:199-210.

43. Panigrahi S, Basu S, Praharaj S, Pande S, Jana S, Pal A, Ghosh SK, Pal T: Synthesis and size-selective catalysis by supported gold nanoparticles: study on heterogeneous and homogeneous catalytic process. J Phys Chem C 2007, 111:4596-4605.

44. Gangula A, Podila R, Ramakrishna M, Karnam L, Janardhana C, Rao AM: Catalytic reduction of 4-nitrophenol using biogenic gold and silver nanoparticles derived from Breynia rhamnoides. Langmuir 2011, 27:15268-15274.

doi:10.1186/1477-3155-10-17

Cite this article as: Ghosh et al:: Gnidia glauca flower extract mediated synthesis of gold nanoparticles and evaluation of its chemocatalytic potential. Journal of Nanobiotechnology 2012 10:17.

\section{Submit your next manuscript to BioMed Central and take full advantage of:}

- Convenient online submission

- Thorough peer review

- No space constraints or color figure charges

- Immediate publication on acceptance

- Inclusion in PubMed, CAS, Scopus and Google Scholar

- Research which is freely available for redistribution 